\title{
Exercise-induced laryngeal obstruction: natural history and effect of surgical treatment
}

\author{
Robert Christiaan Maat • Magnus Hilland • \\ Ola Drange Røksund · Thomas Halvorsen • \\ Jan Olofsson · Hans Jørgen Aarstad · John-Helge Heimdal
}

Received: 27 March 2011 / Accepted: 22 May 2011 / Published online: 5 June 2011

(C) The Author(s) 2011. This article is published with open access at Springerlink.com

\begin{abstract}
The current follow-up study concerning the supraglottic type of exercise-induced laryngeal obstruction (EILO) was performed to reveal the natural history of supraglottic EILO and compare the symptoms, as well as the laryngeal function in conservatively versus surgically treated patients. A questionnaire-based survey was conducted $2-5$ years after EILO was diagnosed by a continuous laryngoscopy exercise (CLE) test in 94 patients with a predominantly supraglottic obstruction. Seventy-one patients had been treated conservatively and 23 with laser supraglottoplasty. The questionnaire response rate was 70 and $100 \%$ in conservatively treated (CT) and surgically treated (ST) patients, respectively. A second CLE test was
\end{abstract}

This research was presented at the meeting of the European Laryngological Society in Vienna, Austria, September, 4, 2010.

R. C. Maat $(\bowtie) \cdot$ M. Hilland · J. Olofsson · H. J. Aarstad .

J.-H. Heimdal

Department of Otolaryngology-Head and Neck Surgery,

Haukeland University Hospital, 5021 Bergen, Norway

e-mail: rcmaat@yahoo.com

R. C. Maat · M. Hilland · J. Olofsson · H. J. Aarstad · J.-H. Heimdal

Department of Surgical Sciences, Section for

Otorhinolaryngology and Head and Neck Surgery,

University of Bergen, Bergen, Norway

O. D. Røksund · T. Halvorsen

Department of Pediatrics, Haukeland University Hospital, Bergen, Norway

O. D. Røksund · T. Halvorsen

Department of Clinical Medicine, Section for Pediatrics,

University of Bergen, Bergen, Norway

R. C. Maat

Department of Otolaryngology, Röpcke-Zweers Hospital,

Hardenberg, The Netherlands performed in $14 \mathrm{CT}$ and 19 ST patients. A visual analogue scale on symptom severity indicated improvements in both the groups, i.e. mean values ( \pm standard deviations) declined from $73(20)$ to $53(26)(P<0.001)$ in the CT group and from $87(26)$ to $25(27)(P<0.001)$ in the ST group. At follow-up, ST patients reported lower scores regarding current level of complaints, and higher ability to perform exercise, as well as to push themselves physically, all compared to CT patients $(P<0.001)$. CLE scores were normalized in 3 of $14(21 \%)$ CT and 16 of 19 (84\%) ST patients $(Z=-3.6 ; P<0.001)$. In conclusion, symptoms of EILO diagnosed in adolescents generally decreased during 2-5 years follow-up period but even more after the surgical treatment. Patients with supraglottic EILO may benefit from supraglottoplasty both as to laryngeal function and symptom relief.

Level of evidence $2 \mathrm{~b}$, individual retrospective cohort study.

Keywords Vocal cord dysfunction - Exercise-induced laryngeal obstruction · Follow-up · Exercise-induced laryngomalacia $\cdot$ Stridor $\cdot$ Supraglottoplasty

\section{Introduction}

Exercise-induced stridor is relatively common in young people and is often related to obstruction at the laryngeal level [1]. There is no consensus regarding the diagnostic methods, or classification for this condition, and several suggestions as to nomenclature have been put forward [2]. In this presentation, we use the term exercise-induced laryngeal obstruction (EILO) to denote such a condition.

EILO may be caused by adduction or collapse of supraglottic structures, inappropriate closure of the glottis, or a 
combination of these events [1,3-6]. The diagnosis is most often made in adolescents, and females are most commonly affected $[2-4,7]$. The natural course of EILO is not known. Changes in symptom levels over time may be caused by somatic factors related to growth with natural resolution of the disease and to the factors related to changes of life style, as well as to a changed perception of the disease.

Different treatment strategies have been suggested. Speech-related therapy has been advocated, and may especially have an effect on EILO related to inappropriate closure of the glottis [8, 9]. However, in many patients, obstruction seems to occur mainly in the supraglottic part of the larynx, i.e. supraglottic EILO or exercise-induced laryngomalacia (EIL) [1, 4]. In patients with supraglottic EILO, the treatment according to the principles outlined for pediatric laryngomalacia, i.e. laser supraglottoplasty or epiglottopexy, has been proven efficient $[4,10,11]$. However, long-term effects of surgical treatment, objectively determined by physical findings, have not been published so far.

We have previously developed and validated a method for continuous laryngoscopy during a treadmill exercise test (continuous laryngoscopy exercise test, CLE test) [12]. This method has, for some years, been used for diagnosing and follow-up of patients with EILO [1]. The main objective of the present study is to assess the natural course of the supraglottic type of EILO in the patients diagnosed by the CLE test. Further, we aim to assess the long-term effects from the surgical treatment of supraglottic EILO, which has been offered based on clinical evaluation to selected patients during 2003-2008.

\section{Materials and methods}

\section{Study design and subject description}

This is a retrospective, observational, longitudinal, followup study. The CLE test was developed by our institution in 2002, and reliability and validity in relation to EILO has been assessed in later studies [7, 12]. Since 2002, a majority of patients presenting with the symptoms of inspiratory stridor during exercise have been offered examination with this test. Patients with confirmed EILO were given information about their condition including a review of the video recording from their test. All the patients were given standardized treatment advise focusing mainly on breathing techniques during exercise, hereafter called conservative treatment $(\mathrm{CT})[8,9]$.

In the period 2003-2008, patients who demonstrated severe supraglottic EILO were offered laser supraglottoplasty as previously described, hereafter called as surgical treatment (ST). Instructive figures to illustrate our approach have been published previously [13]. The selection of patients for surgery was based on the airflow limitation through the laryngeal inlet due to abnormal anatomy and/or inexpedient motion of the aryepiglottic folds during forced respiration. Patients were offered surgical treatment based on the following criteria: presence of any anatomical abnormality, e.g. prominent cuneiform tubercles in the aryepiglottic folds, and or severe obstruction of the laryngeal inlet, as well as the severe EILO caused-symptoms and motivation for treatment.

Subjects showing only a slight inward collapse of supraglottic structures, but no glottic adduction during maximal exercise were considered as non-EILO patients based on the observations from previous studies and, therefore, not included in this study $[1,7,11,12]$.

In total, 114 patients were diagnosed with EILO by the CLE test between 2002 and 2008. Among these, 20 showed predominantly glottic adduction, whereas 94 showed predominantly supraglottic adduction either alone or followed by a glottic adduction. As surgery was only done among the subjects in this latter group, these 94 were included in the present follow-up study performed 2-5 years (mean 3.6) after the primary diagnosis. Of these patients, 23 were treated with ST, while 71 were given only CT. All these patients were invited to answer a questionnaire considering the current level of respiratory distress during exercise, level of athletic activity, changes in activity since diagnosis, change of respiratory symptoms since the first CLE test, as well as the present consequences for social interaction. Indicated response categories were given in a five step Likert scale. A visual analogue score (VAS) was also used to respond to questions about symptom severity.

A subgroup of 23 CT patients, diagnosed 2002-2005, was offered a second CLE test 2-5 years after the first CLE test. Most of these patients were first examined with CLE test before ST was introduced, and may, thus, be considered as natural course historical controls. Fourteen of these patients were re-tested at average of 52 months after the diagnostic CLE test. They matched the surgically treated patients relatively well with respect to age, gender and primary CLE score. Figure 1 gives an overview. Asthma was either ruled out or treated adequately before entering the study [14].

The study was approved by the Committee on Medical Research Ethics of Western Norway, and informed written consent was obtained from all the patients.

\section{Classification and grading of EILO according to CLE test score}

Videos from all CLE tests were presented randomly and unidentifiable to an experienced laryngologist and scored by the CLE-score method as previously described by Maat et al. [7]. In short, adduction of supraglottic and glottic 
Fig. 1 Schematic overview chart concerning inclusion of patients and questionnaire response

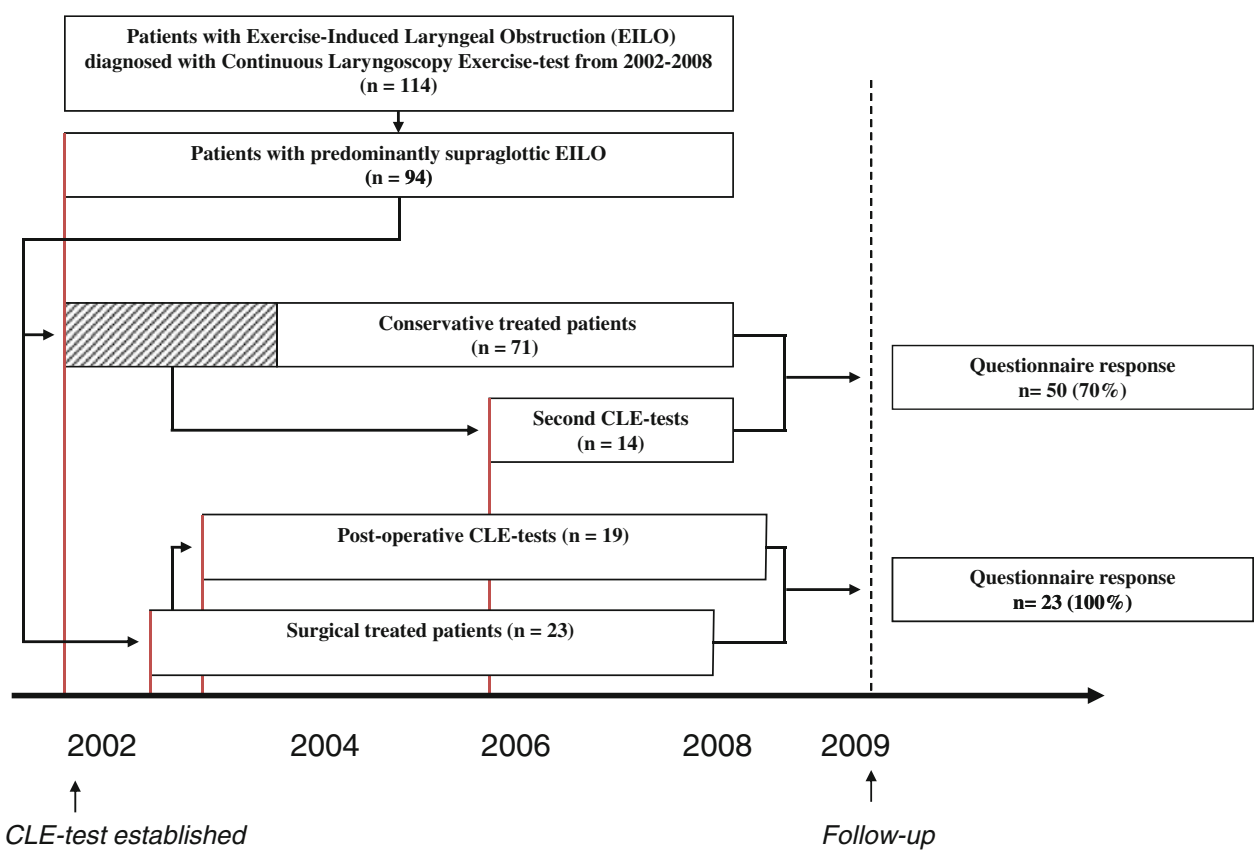

structures of the larynx were scored ranging from normal (0) to maximal adduction (3) twice during test; i.e. at moderate, and maximal effort. This creates four sub-scores labelled A through D and a sum score E. Glottic adductions are represented by $\mathrm{A}$ (moderate effort) and $\mathrm{C}$ (maximal effort), whereas supraglottic adductions are represented by $B$ (moderate effort) and D (maximal effort). We have defined EILO by CLE test sum score E $>2$, whereas glottic EILO was defined by $\mathrm{C}>\mathrm{D}$ and supraglottic EILO was defined by $\mathrm{D} \geq \mathrm{C}$ [7].

\section{Statistical analyses}

In order to compare the observations between the two groups ANOVA analyses of variance were used. Confounding variables, i.e. age, gender, and CLE score were added as co-variables. Comparison of CLE scores before versus after surgery and the first versus second CLE test was analyzed by repeated measure $t$ tests. The Wilcoxon Sign Rank test and the Mann-Whitney test were used in order to validate $t$ test statistics. The calculations were performed with the statistical program SPSS 17.0 (SPSS Science, Chicago, IL, USA). $P$ values $<0.05$ were considered significant.

\section{Results}

The response rate to the questionnaire was 50/71 (70\%) in the CT group and 23/23 in the ST group. Demographic data of the responders are shown in Table 1.
Table 1 Demographic data of patients included in the survey

\begin{tabular}{llll}
\hline Treatment & $\begin{array}{l}\text { Conservative } \\
(n=50)\end{array}$ & $\begin{array}{l}\text { Surgical } \\
(n=23)\end{array}$ & $P$ \\
\hline Gender (male/female) $^{\text {Age }}$ & $14 / 36$ & $9 / 14$ & \\
Follow-up time in days $^{\mathrm{a}}$ & $14.7(3.7)^{\mathrm{b}}$ & $15.1(3.8)$ & $0.679^{\mathrm{c}}$ \\
CLE test sum score $^{\mathrm{d}}$ & $1369(696)$ & $1272(713)$ & 0.585 \\
Supraglottic obstruction $^{\mathrm{f}}$ & $2.4(0.8)$ & $3.9(1.0)$ & $0.072^{\mathrm{e}}$ \\
Glottic obstruction $^{\mathrm{f}}$ & $0.7(0.7)$ & $2.2(0.4)$ & 0.005 \\
\hline
\end{tabular}

a Age at time of diagnosis (first CLE test)

${ }^{\mathrm{b}}$ Data presented as mean (SD)

${ }^{c} P$ value based on independent-samples $t$ test

${ }^{\mathrm{d}}$ CLE score at the first CLE test (diagnosis)

e $P$ value based on Mann-Whitney test

f At maximal intensity

Conservative versus surgical treatment

\section{Symptom severity at follow-up}

Direct comparison of current symptom severity, as assessed by the VAS scores, revealed significantly less symptoms in the ST group compared to the CT group (Fig. 2a). Adjustment for age, gender, and primary CLE score did not change the conclusions (ANOVA co-variate analyses). ST patients reported less breathing difficulties during exercise compared to CT patients, while the activity level declined in both the groups (Table 2). The ST group also scored lower than the CT group on current level of complaints, as well as on the Likert scale 
a

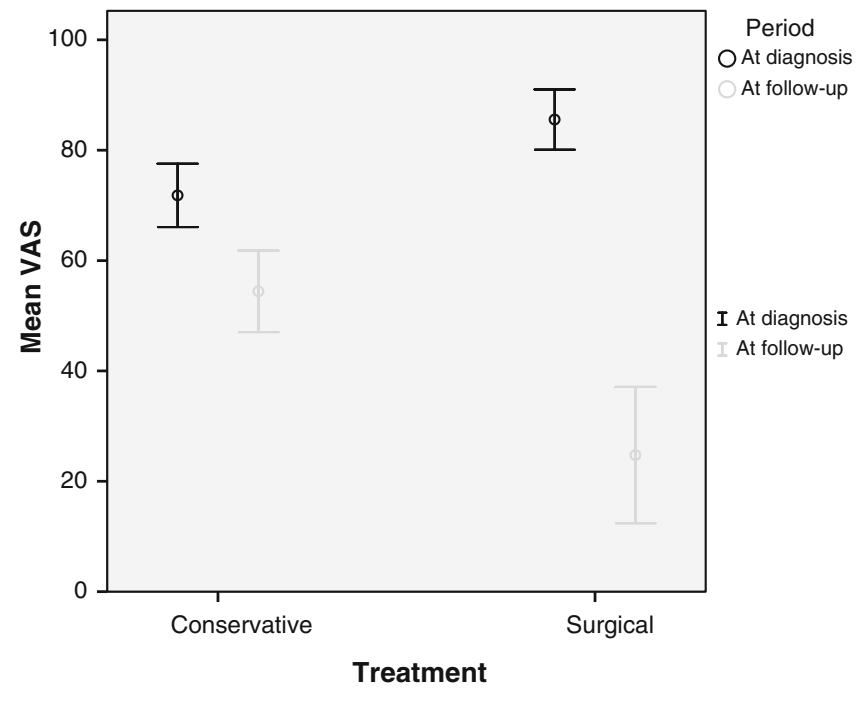

b

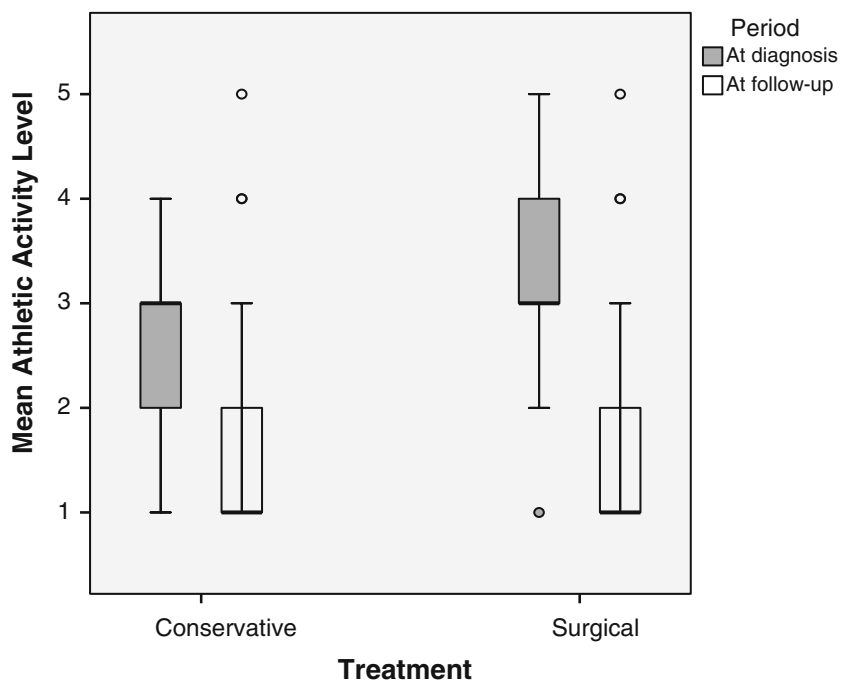

Fig. 2 a Change in severity of exercise-induced laryngeal obstruction symptoms, as given by visual analogue scores between- and within the treated and untreated group (VAS at diagnosis by memory). b Athletic activity level obtained at diagnosis compared to the follow-up

Table 2 Follow-up question response
${ }^{\text {a }}$ Figures are percentages of group

b $P$ value based on Chi-square test

\begin{tabular}{llcr}
\hline Treatment & $\begin{array}{l}\text { Conservative } \\
(n=50)\end{array}$ & $\begin{array}{c}\text { Surgical } \\
(n=23)\end{array}$ & $P$ \\
\hline What has happened since examination? & & & $<0.001^{\text {b }}$ \\
I have presently no breathing difficulties during exercise & $0^{\text {a }}$ & 34 & 0.020 \\
The breathing difficulties have become less & 32 & 62 & $<0.001$ \\
The breathing difficulties have not changed & 60 & 4 & 0.163 \\
The breathing difficulties have become worse & 8 & 0 & 0.141 \\
Are you still active? & & 39 & 0.114 \\
I am less active for other reasons than breathing difficulties & 24 & 9 & 0.056 \\
I am less active because of my breathing difficulties & 24 & 13 & 0.034 \\
I am as active now as I was at the time of the examination & 34 & 39 & \\
I am more active & 16 & 0 & \\
Missing answers & 2 & &
\end{tabular}

"what is your current level of complaints" did decline as well, as did the level of athletic activity which decreased in both the groups, respectively (Fig. 2b).

Improvement in symptoms as assessed by delta-VAS scores (subtracting VAS score from follow-up from VAS scores at diagnosis) was significantly more pronounced in the ST compared to the CT group (Table 3). The ST patients furthermore showed a more pronounced reduction as to delta values of current level of complaints than the CT patients. The delta values as to level of athletic activity did not differ between the groups (Table 3).

CLE test scores at diagnosis versus follow-up

A follow-up CLE test was performed in $14 \mathrm{CT}$ patients and 19 ST patients. Maximal heart rate was comparable at the 
Table 3 Follow-up question response

\begin{tabular}{|c|c|c|c|}
\hline Treatment & Conservative $(n=50)$ & Surgical $(n=23)$ & $P$ \\
\hline What is your current level of complaints? & $2.6(0.7)^{\mathrm{a}}$ & $1.9(0.8)$ & $0.001^{\mathrm{b}}$ \\
\hline My breathing difficulties have been distressing & $2.5(1.2)$ & $2.6(1.3)$ & 0.894 \\
\hline The difficulties have led to less social interaction & $1.5(0.8)$ & $1.5(0.9)$ & 0.919 \\
\hline The difficulties have made me feel sad & $3.0(1.2)$ & $2.7(1.2)$ & 0.330 \\
\hline The difficulties have kept me from achieving what I wanted & $3.1(1.2)$ & $3.3(1.1)$ & 0.485 \\
\hline I have breathing difficulties when I am at rest & $1.3(0.6)$ & $1.1(0.4)$ & 0.178 \\
\hline I get breathing difficulties during physical activity & $3.2(1.1)$ & $2.2(1.3)$ & 0.002 \\
\hline I hear sounds from my airways when I am physical active & $2.7(1.2)$ & $2.2(1.1)$ & 0.105 \\
\hline My breathing difficulties prevent me from exercising & $2.2(1.4)$ & $1.5(1.2)$ & 0.040 \\
\hline I get frightened when the breathing difficulties occur & $2.0(1.2)$ & $1.8(1.4)$ & 0.532 \\
\hline I tend to not push myself physically because of my symptoms & $2.7(1.4)$ & $1.6(0.9)$ & 0.001 \\
\hline My symptoms continue even after stop & $2.1(1.1)$ & $1.8(1.1)$ & 0.173 \\
\hline Delta $\operatorname{VAS}^{\mathrm{c}}(\%)$ & $17.4(28.0)$ & $60.9(25.3)$ & $<0.001$ \\
\hline Delta current level of complaints ${ }^{c}$ & $0.4(0.9)$ & $1.7(0.9)$ & $<0.001$ \\
\hline Delta level of athletic activity ${ }^{\mathrm{c}}$ & $1.0(1.0)$ & $1.3(1.1)$ & 0.257 \\
\hline
\end{tabular}

${ }^{\mathrm{a}}$ Data presented as mean (SD)

${ }^{\mathrm{b}} P$ value based on independent-samples $t$ test

${ }^{c}$ Values from questions at follow-up subtracted from the same questions at inclusion

Table 4 Scores from the continuous laryngoscopy exercise test (CLE test) at diagnosis and at follow-up in patients examined twice

\begin{tabular}{|c|c|c|c|c|c|c|}
\hline \multirow[t]{2}{*}{ Treatment } & \multicolumn{3}{|c|}{ Surgical $(n=19)$} & \multicolumn{3}{|c|}{ Conservative $(n=14)$} \\
\hline & At diagnosis & At follow-up & $P$ & At diagnosis & At follow-up & $P$ \\
\hline CLE test sum score & $4.3(1.2)^{\mathrm{a}}$ & $2.1(0.7)$ & $<0.001^{\mathrm{b}}$ & $4.1(0.9)$ & $3.4(1.2)$ & $0.027^{\mathrm{b}}$ \\
\hline Supraglottic score & $3.0(0.8)$ & $1.7(0.6)$ & $<0.001$ & $2.8(0.6)$ & $2.4(0.9)$ & 0.082 \\
\hline Glottic score & $1.3(0.9)$ & $0.4(0.5)$ & $<0.001$ & $1.3(0.6)$ & $1.0(0.6)$ & 0.040 \\
\hline
\end{tabular}

${ }^{a}$ Data presented as mean (SD)

b $P$ value based on paired-samples $t$ test

diagnostic and the follow-up CLE test both in the CT and in the ST patients.

In CT patients, mean CLE test sub-score $\mathrm{C}$ (glottic obstruction), D (supraglottic obstruction), and sum score E did decline from initial diagnosis to the follow-up (Table 4). Laryngeal function during exercise had normalized in 3 of the 14 patients, i.e. a CLE test sum scores reduced to 2 or lower. In the 19 ST patients who had been examined twice with the CLE test, mean sub-score C, D and sum-score $\mathrm{E}$ were reduced from diagnosis to follow-up as well (Table 4). However, laryngeal function during exercise had normalized in 16 out of 19 patients in this group $(\mathrm{E} \leq 2)$. The rate of normalized CLE test sum-scores were significantly higher in the surgically treated group compared to the CT group (16/19 versus $3 / 14, Z=-3.6$; $P<0.001)$.

A delta CLE score was calculated by subtracting the CLE test sub-scores at follow-up from the CLE test sub- scores at diagnosis. Mean delta CLE score C, D, and sum score $\mathrm{E}$ were significantly larger in the ST group compared to the CT control group. This is illustrated by Fig. 3. Direct comparison of CLE test sum scores (E) at follow-up also revealed significantly better results for the ST group compared to the CT group.

\section{Discussion}

This is one of the first follow-up studies of exerciseinduced laryngeal obstruction in the large groups of patients, where direct laryngoscopy during ongoing heavy exercise has been used as a diagnostic method. The study concludes that symptoms and laryngeal function improved slightly in the patients treated with information alone, but that surgical treatment (ST) in patients with a supraglottic obstruction induced by exercise was significantly more 


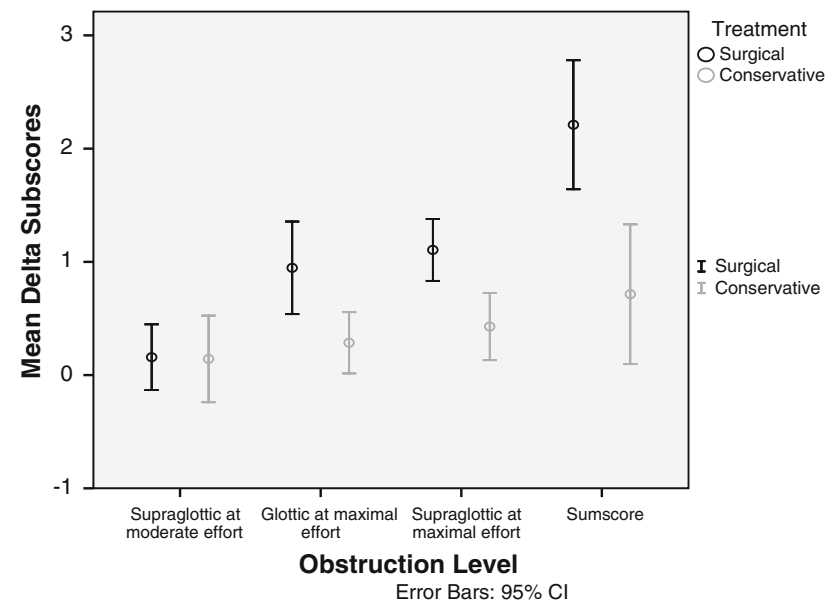

Fig. 3 Change in continuous laryngoscopy exercise sub-scores for patients without treatment and surgically treated patients where the CLE score from the second CLE test is subtracted from the first CLE test (the vocal folds showed normal abduction at moderate effort in all the cases, therefore, this is not shown)

effective measured both at the supraglottic and glottic levels. Laryngeal function had normalized in 16/19 (84\%) patients treated with laser supraglottoplasty compared to $3 /$ $14(21 \%)$ conservatively treated (CT) patients. Furthermore, asthma had been either ruled out or appropriately treated before entering the study and lung function data were similar between the twice CLE tested subgroups of the study [14].

In this study, the CLE test was used as the method to assign a diagnosis of EILO and thereby formed the basis for standardized inclusion of patients with EILO related symptoms. The CLE score has previously been shown to be a valid method for evaluating the grade of EILO. Still, the separation between CT and ST patients was not randomly made but based mainly on the clinical decisions. However, most of the CT patients studied twice with CLE test are the patients diagnosed before ST was introduced and, thus represent the historical controls. The two groups were furthermore relatively comparable with respect to gender, age and diagnostic CLE test scores.

The lower response in CT group than in ST may be an indication that ST patients, in general, are more satisfied with the treatment and follow-up which could influence on how they answer the questionnaire. Still, differences regarding the expectations and perception of symptoms may have biased symptom description in both the groups. To reduce some of these possible sources of bias, as well as to add a registry-based cohort dimension to the study, symptoms in ST patients were compared to symptoms in all the CT patients with supraglottic EILO diagnosed at our centre, with no changed conclusions. ST was applied on selected EILO cases, but in a definite period of time. This made it possible to include the CT patients that could potentially have been treated surgically, i.e. historical controls, as CLE twice tested controls. This further strengthens the present conclusion about the effect of surgery. Furthermore, CLE scores discriminated between CT and ST patients at follow up. It is difficult to conceive that a placebo effect could change larynx anatomy during exercise. Still, presentation and perception of symptoms may have been biased by surgical treatment. Ideally CT and ST patients should have been compared in a randomized prospective study. Our study reveals that surgery indeed seems to be efficient in selected EILO cases and may, therefore, be applied as one arm in the future randomized studies.

Both the ST, as well as the total group of CT patients reported relief of symptoms at follow-up, although to a significantly greater extent in the former group. This difference between the two groups persisted also after adjustment by age and gender of subjects, as well as the adjustment by primary CLE scores. It is, therefore, supported that surgery in selected cases may have a long lasting positive effect on EILO related symptoms.

In this study, only subjects with clear exercise-induced symptoms, who were highly motivated for treatment, were offered ST. Severe exercise-induced adduction of aryepiglottic folds was demonstrated during CLE test as well [13]. The post-operative CLE test revealed that laryngeal function was improved in all but one and normalized in 16 out of 19 tested after surgery. Interestingly, this study shows that surgical treatment at the supraglottic level in EILO patients seems to have a positive effect on obstruction at the glottic level as well. The mechanism behind this noticeable fact should be sorted out in future studies. Still, some patients reported symptoms during exercise. One of the 23 ST patients reported breathing difficulties and stridor, while exercising in cold weather postoperatively. Postoperative CLE test in room temperature demonstrated normalization of laryngeal function. One may speculate that increasing the size of the laryngeal introitus by supraglottoplasty in this particular case have changed the threshold for the protective glottic reflex [15].

Growth of upper airways together with enlargement of laryngeal diameter enables the airway to respond better to increased need for airflow in adults compared to the juveniles [16]. EILO is the most often diagnosed in adolescents, which suggests natural resolution through maturation and growth of the larynx [17-20]. The fact that CT patients in general reported persisting symptoms at follow-up and laryngeal function had normalized in only 3 out of 14 retested control patients argues against such a hypothesis. This study supports that EILO in general does not spontaneous resolve the following maturation.

Participation in physical activities is associated with better health [21]. Studies have shown that young people, moving from high school to college, are at the risk of inac- 
Fig. 4 Proposed flow chart for treatment of EILO, based on clinical experience until now. Prospective studies are required to establish evidence-based treatment algorithms for patients with EILO

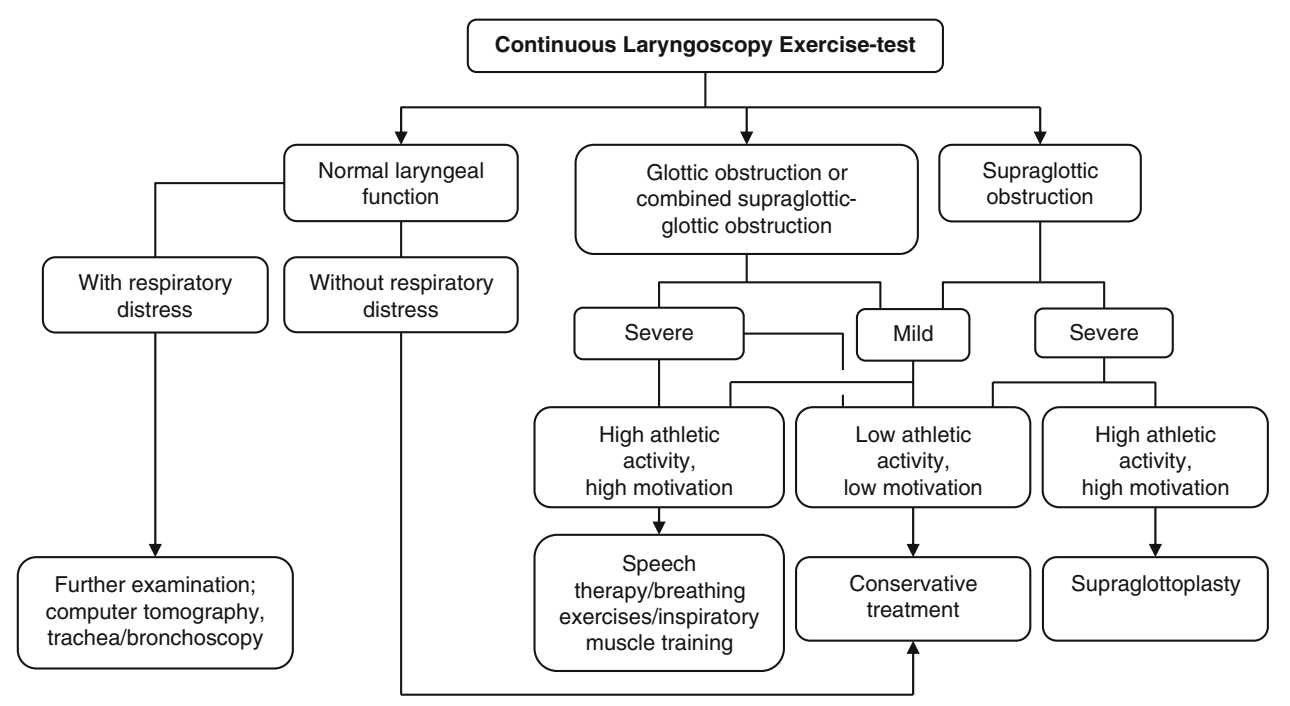

tivity and weight gain with potential negative consequences for their adult health [21-23]. Suboptimal treatment of EILO may, therefore, represent an additional health risk for these patients, which argues in favour of treatment of these patients.

Although surgery in this study turned out to be an efficient treatment in selected cases with supraglottic EILO, we cannot rule out the effects of systematic prolonged CT like inspiratory muscle strength training [24], respiratory retraining therapy $[25,26]$ or speech therapy [8]. Based on our clinical experience we have prepared a flow chart that shows how we currently treat our patients (Fig. 4). This is our present suggestion and further recommendations as to the treatment of EILO, should be based on conclusions from future prospective randomized studies. A more precise nomenclature is also needed in this aspect in order to guarantee that one compares exactly the same type of pathological conditions in different treatment protocols. This issue has been discussed in the European Laryngological Society (ELS) and the European Respiratory Society (ERS). A joint ELS/ERS Task Force has recently been established to develop the common guidelines.

\section{Conclusion}

This follow-up study concludes that young patients diagnosed with supraglottic EILO, and treated with information alone, experience some relief of symptoms after a followup period of 2-5 years, but that laryngeal function during exercise normalize in a minority, compared to a majority in a surgically treated group.

Patients with severe supraglottic EILO may be treated surgically with long lasting positive effect on symptoms, as well as on laryngeal function.
Randomized, controlled, and prospective trials are required to establish the evidence-based treatment algorithms for patients with EILO.

Acknowledgments The authors are grateful to Thor Andre Ellingsen for excellent work on video- and figure editing, and assistance during numerous CLE tests. The major funding institution is Haukeland University Hospital and the University of Bergen, Norway. Furthermore, this work was supported by The Western Norway Regional Health Authority.

Conflict of interest Haukeland University Hospital owns parts of a US patent protecting the commercial rights to the CLE test. Sponsors were not involved and had no impact on the study design, in the collection, analysis, and the interpretation of data, in the writing of the report, nor in decision to submit the article for publication.

Open Access This article is distributed under the terms of the Creative Commons Attribution Noncommercial License which permits any noncommercial use, distribution, and reproduction in any medium, provided the original author(s) and source are credited.

\section{References}

1. Roksund OD, Maat RC, Heimdal JH, Olofsson J, Skadberg BT, Halvorsen T (2009) Exercise induced dyspnea in the young. Larynx as the bottleneck of the airways. Respir Med 103:1911-1918

2. Christopher KL, Morris MJ (2010) Vocal cord dysfunction, paradoxic vocal fold motion, or laryngomalacia? our understanding requires an interdisciplinary approach. Otolaryngol Clin North Am 43:43-66 viii

3. Bjornsdottir US, Gudmundsson K, Hjartarson H, Brondbo K, Magnusson B, Juliusson S (2000) Exercise-induced laryngochalasia: an imitator of exercise-induced bronchospasm. Ann Allergy Asthma Immunol 85:387-391

4. Smith RJ, Bauman NM, Bent JP, Kramer M, Smits WL, Ahrens RC (1995) Exercise-induced laryngomalacia. Ann Otol Rhinol Laryngol 104:537-541

5. Hicks M, Brugman SM, Katial R (2008) Vocal cord dysfunction/ paradoxical vocal fold motion. Prim Care 35:81-103 vii

6. Morris MJ, Christopher KL (2010) Diagnostic criteria for the classification of vocal cord dysfunction. Chest 138:1213-1223 
7. Maat RC, Roksund OD, Halvorsen T, Skadberg BT, Olofsson J, Ellingsen TA, Aarstad HJ, Heimdal JH (2009) Audiovisual assessment of exercise-induced laryngeal obstruction: reliability and validity of observations. Eur Arch Otorhinolaryngol 266:1929_ 1936

8. Sullivan MD, Heywood BM, Beukelman DR (2001) A treatment for vocal cord dysfunction in female athletes: an outcome study. Laryngoscope 111:1751-1755

9. Murry T, Tabaee A, Aviv JE (2004) Respiratory retraining of refractory cough and laryngopharyngeal reflux in patients with paradoxical vocal fold movement disorder. Laryngoscope 114:1341-1345

10. Mandell DL, Arjmand EM (2003) Laryngomalacia induced by exercise in a pediatric patient. Int $\mathrm{J}$ Pediatr Otorhinolaryngol 67:999-1003

11. Bent JP 3rd, Miller DA, Kim JW, Bauman NM, Wilson JS, Smith RJ (1996) Pediatric exercise-induced laryngomalacia. Ann Otol Rhinol Laryngol 105:169-175

12. Heimdal JH, Roksund OD, Halvorsen T, Skadberg BT, Olofsson J (2006) Continuous laryngoscopy exercise test: a method for visualizing laryngeal dysfunction during exercise. Laryngoscope 116:52-57

13. Maat RC, Roksund OD, Olofsson J, Halvorsen T, Skadberg BT, Heimdal JH (2007) Surgical treatment of exercise-induced laryngeal dysfunction. Eur Arch Otorhinolaryngol 264:401-407

14. Carlsen KH, Carlsen KC (2002) Exercise-induced asthma. Paediatr Respir Rev 3:154-160

15. Shiba K, Isono S, Nakazawa K (2007) Paradoxical vocal cord motion: a review focused on multiple system atrophy. Auris Nasus Larynx 34:443-452

16. Kahane JC (1978) A morphological study of the human prepubertal and pubertal larynx. Am J Anat 151:11-19
17. Bittleman DB, Smith RJ, Weiler JM (1994) Abnormal movement of the arytenoid region during exercise presenting as exercise-induced asthma in an adolescent athlete. Chest 106:615-616

18. Abu-Hasan M, Tannous B, Weinberger M (2005) Exercise-induced dyspnea in children and adolescents: if not asthma then what? Ann Allergy Asthma Immunol 94:366-371

19. Castelli WA, Ramirez PC, Nasjleti CE (1973) Linear growth study of the pharyngeal cavity. J Dent Res 52:1245-1248

20. Kahane JC (1982) Growth of the human prepubertal and pubertal larynx. J Speech Hear Res 25:446-455

21. Pearson N, Atkin AJ, Biddle SJ, Gorely T, Edwardson C (2009) Patterns of adolescent physical activity and dietary behaviours. Int J Behav Nutr Phys Act 6:45

22. Kimm SY, Glynn NW, Kriska AM, Fitzgerald SL, Aaron DJ, Similo SL, McMahon RP, Barton BA (2000) Longitudinal changes in physical activity in a biracial cohort during adolescence. Med Sci Sports Exerc 32:1445-1454

23. Wengreen HJ, Moncur C (2009) Change in diet, physical activity, and body weight among young-adults during the transition from high school to college. Nutr J 8:32

24. Ruddy BH, Davenport P, Baylor J, Lehman J, Baker S, Sapienza C (2004) Inspiratory muscle strength training with behavioral therapy in a case of a rower with presumed exercise-induced paradoxical vocal-fold dysfunction. Int J Pediatr Otorhinolaryngol 68:1327-1332

25. Christopher KL, Wood RP 2nd, Eckert RC, Blager FB, Raney RA, Souhrada JF (1983) Vocal-cord dysfunction presenting as asthma. N Engl J Med 308:1566-1570

26. Murry T, Tabaee A, Owczarzak V, Aviv JE (2006) Respiratory retraining therapy and management of laryngopharyngeal reflux in the treatment of patients with cough and paradoxical vocal fold movement disorder. Ann Otol Rhinol Laryngol 115:754-758 